\title{
Inducible nitric oxide synthase in the cardiovascular system
}

Many acute and chronic diseases of the cardiovascular system are characterised by an inflammatory response. Atherogenesis is considered a chronic inflammatory disease of the vessel wall, ${ }^{1}$ acute or chronic inflammation of the myocardium underlies certain forms of cardiomyopathy, ${ }^{2}$ and severe acute inflammation secondary to infection (septic shock) leads to profound changes in the behaviour of blood vessels and the heart. ${ }^{3}$ An understanding of the processes underlying vascular inflammation should lead to novel approaches to treatment, and one pathway, the L-arginine:nitric oxide (NO) pathway, is currently arousing considerable interest as a fundamental mechanism of inflammation and a potential target for novel therapies.

\section{Nitric oxide synthases}

Three NO synthases have been identified-an endothelial type (eNOS), a neuronal type (nNOS), and a macrophage type that is known as inducible NOS (iNOS). Endothelial and neuronal NO synthases are normal constituents of healthy cells and synthesise NO to facilitate cell-cell communication. Both enzymes seem to have important roles in the regulation of the cardiovascular system and, paradoxically, both seem also to be "inducible" in response to certain stimuli including oestrogens. ${ }^{4}$ These two isoforms of NO synthase have been reviewed extensively elsewhere and are not considered further in this article. ${ }^{56}$ The third isoform, the classic inducible NOS (iNOS) is not a normal constituent of quiescent healthy cells but is expressed in a wide variety of cell types after they are exposed to bacterial endotoxin or combinations of inflammatory cytokines. ${ }^{78}$ Initially described in mouse macrophages, expression of this enzyme leads to prolonged synthesis of large amounts of NO. The NO produced by macrophages is an important component of what was known as "non-specific immunity" and is toxic to various pathogens including many protozoa $^{9}$ and fungi, ${ }^{10}$ certain bacteria, ${ }^{11}$ and viruses. ${ }^{12}$ Host cells are not exempt from the toxic effect of $\mathrm{NO}$ and, while NO may be useful to inhibit growth and replication of abnormal cells including malignant cells, damage to healthy cells also occurs: endothelial cell damage and increased vascular permeability may result from overproduction of NO. ${ }^{713}$ Within the cardiovascular system, expression of iNOS has been implicated as a mechanism of tissue dysfunction and damage in several disease states. ${ }^{614-16}$ How strong is the evidence and are there opportunities for new therapies based on manipulation of iNOS activity?

\section{Animal models}

After exposure to bacterial endotoxin or certain cytokines (notably interleukin-1 and tumour necrosis factor $\alpha$ ), expression of iNOS occurs throughout the cardiovascular system, in vascular endothelial cells, ${ }^{17}$ smooth muscle cells, ${ }^{18}$ endocardium, ${ }^{19}$ and macrophages located within the vessel wall. ${ }^{20}$ Overproduction of $\mathrm{NO}$ in the blood vessel wall is associated with vasodilatation, resistance to con- strictor stimuli, and endothelial cell damage or dysfunction. ${ }^{714}$ In the heart NO inhibits contraction in isolated cardiac myocytes, ${ }^{19} 21$ strips of papillary muscle, or intact perfused hearts. ${ }^{22}$

Despite the clear biochemical and molecular biological evidence for the presence of iNOS protein, determining its contribution to pathophysiological changes has been less straightforward. Most of the inhibitors of NO synthesis that are currently available do not distinguish significantly between the three isoforms of NOS (eNOS, nNOS, and iNOS) and the overall effect produced by these compounds is a composite one, not due solely to inhibition of iNOS. However, recent experiments with inhibitors showing a degree of selectivity for iNOS have demonstrated the importance of this enzyme type in mediating the hypotensive and toxic effects of endotoxin. ${ }^{23}$ Furthermore, "geneknockout" experiments, in which the iNOS gene was disrupted in stem cells to produce adult mice lacking iNOS, have found that the mice without iNOS are more sensitive to certain infections with live organisms but resistant to the hypotensive and lethal effects of endotoxin. ${ }^{24} 25$ These studies confirm the role of induction of iNOS as a host defence mechanism and also clearly indicate its potential to damage the host, at least in endotoxaemia. Using similar techniques it should now be possible to identify more precisely the role of iNOS in models of chronic cardiovascular inflammation including atherogenesis and cardiomyopathy.

\section{How does NO cause damage?}

The mechanism by which expression of iNOS leads to cytotoxicity is uncertain. Many of the physiological effects of NO are mediated by interaction with the haem moiety of the enzyme guanylate cyclase and it is possible that toxic effects are due to interaction with haem or iron-sulphur centres of other enzymes. ${ }^{26}$ Nitric oxide inhibits mitochondrial respiration, ${ }^{27}$ damages $\mathrm{DNA},{ }^{28}$ and inhibits replication of cells including vascular smooth muscle cells. ${ }^{18}$ At higher concentrations NO reacts rapidly with oxygen and in the presence of $\mathrm{O}_{2}^{-}$(superoxide anion, another product of the inflammatory response) NO forms ONOO (peroxynitrite). Depending on the local environment and thiol concentration, peroxynitrite might either revert to NO, cause damage by leading to nitration, or lead to generation of other toxic radicals including $\mathrm{OH}^{-}$(hydroxyl radical) ${ }^{29}$ It remains to be determined why normal physiological production of NO is protective in the cardiovascular system and may prevent atheroma formation ${ }^{30} 31$ whereas excess NO produced after expression of iNOS and under conditions of inflammation, is potentially harmful.

\section{Inducible NOS in humans}

The gene encoding iNOS in humans is located on chromosome $17^{32}$; message for iNOS has been found in human hepatocytes ${ }^{33}$ and vascular smooth muscle cells ${ }^{34}$ exposed to cytokines or endotoxin, and immunohistochemistry has 
identified the iNOS protein in macrophages ${ }^{35}$ harvested from patients with inflammatory conditions. Expression of active iNOS has been demonstrated in cytokine-activated human vascular smooth muscle cells and endothelial cells in culture ${ }^{1836}$ and addition of endotoxin to isolated blood vessels leads to vascular relaxation and functional changes consistent with expression of iNOS and overproduction of NO. Furthermore, there are biochemical and functional data to support a role for iNOS in the vasodilatation and hypotension of septic shock in patients. ${ }^{37}$ Recently it has been suggested that iNOS is expressed in aneurysmal atherosclerotic human aorta ${ }^{17}$ and in the megakaryocytes of patients with atherosclerosis. ${ }^{16}$

There is therefore, evidence that iNOS can be expressed in the vessel wall of humans, produces biological effects, and is present under conditions of acute and chronic inflammation. iNOS activity has also been found in ventricular biopsies of patients with dilated cardiomyopathy ${ }^{2}$ but experimental induction of iNOS in human myocytes or endocardial cells in response to endotoxin or cytokines has not yet been demonstrated. Studies with NO-donor drugs suggest that overproduction of NO in the human heart might decrease contractility and impair diastolic relaxation. ${ }^{38}$

The precise role of iNOS in human cells has been a topic of considerable debate, but it has now been demonstrated that expression of iNOS in human macrophages leads to production of NO in amounts sufficient to kill pathogens, ${ }^{39}$ suggesting that as in animals, iNOS is potentially an important host defence mechanism. Together, the data indicate that iNOS is expressed in the human cardiovascular system under conditions of inflammation, that the NO produced might be a mechanism of host defence, and that the effects of the expression of iNOS in the cardiovascular system include changes in cardiac and vascular function and tissue (including endothelial) damage. At least some of these effects are unwanted and potentially damaging to the host; a classic concept of immunopathology.

\section{Therapeutic possibilities}

Physiological production of NO from constitutive NOS in endothelium and nerves is important to maintain cardiovascular homoeostasis ${ }^{6}$ and expression of iNOS seems to be important for host defence against intracellular pathogens. Currently there is therapeutic interest in boosting physiological levels of NO. Are drugs that inhibit NOS likely to do more harm than good? Available NOS inhibitors that have been used in humans do not distinguish between eNOS, nNOS, and iNOS. One of these, $N^{G}$ monomethyl-L-arginine (L-NMMA) has been given to patients with septic shock and it is clear that blocking NOS in sepsis restores blood pressure and arterial tone but cardiac output falls, probably in response to the increased arterial resistance. ${ }^{37}$ However, in vivo and in vitro animal studies suggest that expression of iNOS in the heart itself contributes to the myocardial depression associated with sepsis and it would be important to establish the direct effect of inhibition of NO in the human heart in health and disease. Large trials of the clinical efficacy of $L$ NMMA in septic shock are underway and should determine whether non-specific inhibition of NOS will be of therapeutic benefit in this acute condition of vast overproduction of NO.

For other more chronic conditions, selective inhibitors of iNOS offer more promise. Certainly as this type of drug becomes more widely available for investigative use in animals $^{23}$ and eventually also in humans, it should be possible to determine the importance of iNOS in the pathogenesis of damaging inflammatory reactions in the cardiovascular system including dilated cardiomyopathy and atherogenesis. However, even if chronic expression of iNOS has a major role in these conditions (and currently this seems plausible) it is unlikely that inhibitors of the enzyme will be free from problems: increased susceptibility to certain types of infection is a possible unwanted effect. The challenge will be to identify when the excess $\mathrm{NO}$ is providing protection and when it is causing damage to the host. The answer may lie in never aiming for more than incomplete inhibition of iNOS.

K BHAGAT

Centre for Clinical Pharmacology, P VALLANCE

Cruciform Project and Department of Medicine,

University College London

1 Ross R. The pathogenesis of atherosclerosis: a perspective for the '90s. Nature 1993;362:801-9.

2 de Belder AJ, Radomski MW, Why HJ, Bucknall CA, Salas E, Martin JF, Moncada S. Nitric oxide synthase activities in human myocardium. Lancet 1993;341:84-5.

3 Snell JR, Parrillo JE. Cardiovascular dysfunction in septic shock. Chest 1991;99:1000-9.

4 Weiner CP, Lizasoain I, Bayliss SA, Knowles RG, Charles IG, Moncada S. Induction of $\mathrm{Ca}^{++}$dependent NO synthesis by sex hormones. Proc Natl Acad Sci 1994;91:5212-6.

5 Sessa WC. The nitric oxide synthase family of proteins. $f$ Vasc Res 1994; 31:131-43.

6 Calver A, Collier J, Vallance P. Nitric oxide and cardiovascular control. Exp Physiol 1993;78:303-26.

7 Nathan C. Nitric oxide as a secretory product of mammalian cells. FASEB f 1992;6:3051-64.

8 Rees DD, Cunha FQ, Assreuy J, Herman AG, Moncada S. Sequential induction of nitric oxide by Corynebacterium parvum in different organs of the mouse. Br $\mathcal{F}$ Pharmacol 1995;114:689-3.

9 Assreuy J, Cuhna FQ, Epperlein M, Noronha-Dutra A, O'Donnell CA, Liew FY, Moncada S. Production of nitric oxide and superoxide by activated macrophages and killing of Leishmania major. Eur $\mathcal{f}$ Immunol 1994; vated macrop

10 Lee SC, Dickson, Brosnan SF, Casadevell A. Human astrocyes inhibit Cryptococcus neoformans by a nitric oxide-mediated mechanism. $\mathcal{f}$ Exp Med 1994;180:365-9.

11 Brunelli L, Crow JP, Beckman JS. The comparative toxicity of nitric oxide and peroxynitirite to Escherichia coli. Arch Biochem Biophys 1995;316 327-34.

12 Karupiah G, Xie QW, Buller RM, Nathan C, Mackmicking JD. Inhibition of viral replication by interferon-gamma-induced nitric oxide synthase. Science 1993;261:1445-8.

13 Beckamn JS, Crow JP. Pathological implications of nitric oxide, superoxide and peroxynitrite formation. Biochem Soc Trans 1993;21:330-4

14 Vallance $P$, Moncada S. Role of endogenous nitric oxide in septic shock. New Horizons 1993;1:77-86.

15 Deng AY, Rapp JP. Locus for the inducible but not constitutive nitric oxide synthase cosegregates with blood pressure in dahl salt-sensitive rats. $\mathcal{F}$ Clin Invest 1995;95:2170-204.

16 de Belder A, Radomski M, Hancock V, Brown A, Moncada S, Martin J. Megakaryocytes from patients with coronary atherosclerosis express the inducible nitric oxide synthase. Arterioscler Thromb Vasc Biol 1995;15: inducible

17 Morris SM, Billiar TR. New insights into the regulation of inducible nitric oxide synthesis. Am $\mathcal{F}$ Physiol 1994;266:E829-39.

18 Schini VB, Vanhoutte PM. Role of the L-arginine-nitric oxide pathway in vascular smooth muscle. Eur Heart f 1993;14:S16-21.

19 Balligand JL, Ungureanu-Longgrois D, Simmons WW, Pimenal D, Malinski TA, Kapturczak M, et al. Cytokine-inducible nitric oxide synthase (iNOS) expression in cardiac myocytes. Characterisation and regulation of iNOS expression and detection of iNOS activity in single cardiac myocytes in vitro. $\mathcal{F}$ Biol Chem 1994;269:27580-8.

20 Cook TH, Bune AJ, Taylor M, Loi RK, Cattel V. Cellular localisation of inducible nitric oxide in endotoxic shock in the rat. Clin Sci 1994;87: 179-86.

21 Brady AJ, Poole-Wilson PA, Harding SE, Warren JB. Nitric oxide production within cardiac myocytes. Am F Physiol 1992;263:H1963-6.

22 Grocott-Mason R, Anning P, Evans H, Lewis MJ, Shah AJ. Modulation of left ventricular relaxation in isolated ejecting heart by endogenous nitric oxide. Am $\mathcal{F}$ Physiol 1994;267:H1804-13.

23 Southan GJ, Szabo C, Thiemermann C. Isothioureas: potent inhibitors of nitric oxide synthases with variable isoform selectivity. Br $\mathcal{f}$ Pharmacol nitric oxide syn

24 Wei X, Charles IG, Smith A, Ure J, Feng G, Huang F, et al. Altered immune responses in mice lacking inducible nitric oxide synthases. Nature 1995;375:408-11.

25 MacMicking JD, Nathan C, Hom G, Chartrain N, Fletcher DS, Trumbauer $M$, et al. Altered responses to bacterial infection and endotoxic shock in mice lacking inducible nitric oxide synthase. Cell 1995;81 $641-50$

26 Radi R, Beckman JS, Bush KM, Freeman BA. Peroxynitrite oxidation of sulfhydryls. The cytotoxic potential of superoxide and nitric oxide. $\mathcal{F}$ Bio Chem 1991;266:4244-50.

27 Dijkmans R, Billiau A. Interferon- $\gamma$ /lipopolysaccharide-treated mouse embryonic fibroblasts are killed by a glycoysis/L-arginine-dependen process accompanied by depression of mitochondrial respiration. Eur $\mathscr{f}$ Biochem 1991;202:151-9.

28 Nguyen T, Brunsen D, Crespi CI, Penman BW, Wishnok JS Tannenbaum SR. DNA damage and mutation in human cells exposed to nitric oxide in vitro. Proc Natl Acad Sci 1992;89:3030-4 
29 Moro MA, Darley-Usmar VM, Goodwin DA, Read NG, Zamora-Pino R, Feelisch M, et al. Paradoxical fate and biological action of peroxynitrite on human platelets. Proc Natl Acad Sci 1994;91:6702-6.

30 Tanner FC, Boulanger CM, Luscher TF. Endothelium-derived nitric oxide, endothelin, and platelet vessel wall interaction: alterations in hypercholesterolaemia and atherosclerosis. Sem Thromb Haem 1993;19: 167-75.

31 Woditsch I, Schror K. Reduced endothelium dependent-relaxation and enhanced NO release in hearts of hypercholesterolaemic rabbits. $B r \mathcal{F}$ Pharmacol 1994,111:1035-40.

32 Marsden PA, Heng HH, Shi XM, Tui LC, Hall AV. Localisation of the human gene nitric oxide synthase (NOS2) to chromosome 17q11-2-q12. Genomics 1994;19:183-5.

33 Geller DA, Lowenstein CJ, Shapiro RA, Nussler AK, Di Silvio M, Wang SC, et al. Molecular cloning and expression of inducible nitric oxide synthase from human hepatocytes. Proc Natl Acad Sci 1993;90:3491-5.

34 Kanno K, Hirata Y, Imai T, Marumo F. Induction of nitric oxide synthase gene by interleukin in vascular smooth muscle cells. Hypertens 1993; 22:34-9.

35 Hamid Q Sprignall DR, Rivieros-Moreno V, Chanez $P$, Howarth $P$, Redington A, et al. Induction of nitric oxide synthase in asthma. Lancet Redington A, et al. Induction of nitric oxide synthase in asthma. Lancet 36 Radomi

, Whitely G, Foxell N, Moncada S. Platelet adhesion to human vascular endothelium is modulated by constitutive and cytokine induced nitric oxide. Cardiovasc Res 1993;27:1380-2.

37 Petros A, Bennett D, Vallance P. Effect of nitric oxide synthesis inhibitors on hypotension in patients with sepsis. Lancet 1991;101:810-5

38 Paulus WJ, Vantrimont PJ, Shah AM. Acute effects of nitric oxide on left ventricular relaxation and diastolic distensibility in humans. Circulation 1994;89:2070-8.

39 Vouldoukis I, Riveiros-Moreno V, Dugas B, Ouaaz F, Becherel P, Debre P et al. The killing of Leishmania major by human macrophages is mediated by nitric oxide after ligation of FceRII/CD23 surface antigen. Proc Nat Acad Sci 1995;92:7804-8. 